\title{
Jwa: notas sobre a oscilação do sangue no corpo e no território dos Iku da Colômbia
}

Ana Milena Horta ${ }^{1}$

Universidade Federal do Rio Grande do Sul

Resumo: A partir do trabalho etnográfico realizado com o povo Iku, da Colômbia, exploro a dinâmica do sangue, jwa, argumentando que é necessário abordar, além dos processos da construção do corpo, as manifestações desta potência vital no território, que é o corpo da Mãe universal. O sangue circula conectando opostos, ao mesmo tempo em que é composto por forças opostas. Dessa forma, ele deve ser entendido a partir de movimentos oscilatórios e não de atributos estáticos. O sangue menstrual tem uma potência que deve ser mediada pelo mamo, a mulher, e potências do território.

Palavras-chave: sangue; Iku; corpo; território; menstruação.

${ }^{1}$ Possui graduação em antropologia pela Universidad de Los Andes, Colômbia (2003). Mestre em Antropologia Social pela Universidade Federal do Rio Grande do Sul, UFRGS (2015). Atualmente cursa o doutorado em Antropologia Social na Universidade Federal do Rio Grande do Sul, UFRGS. 


\title{
Jwa: notes on oscillation of blood on the body and territory of Colombia's Iku
}

\begin{abstract}
From an ethnographic work conducted with the Iku people of Colombia, I explore the dynamics of blood, jwa, arguing that it is necessary to approach, besides the processes of body construction, to the manifestations of that vital force in the territory, which is the body of the Universal Mother. Blood, which is made by opposite forces, circulates around connecting the opposites in the same way. This conception allows us to understand it as oscillatory movements, rather than as static attributes. Menstruation's vital force must be mediated by the mamo, the woman and the territory forces.
\end{abstract}

Keywords: blood; Iku; body; territory; menstruation.

\section{Jwa: notas sobre la oscilación de la sangre en el cuerpo y el territorio de los Iku de Colombia}

Resumen: A partir de trabajo etnográfico realizado con el pueblo Iku de Colombia, exploro la dinámica de la sangre, jwa, argumentando que es necesario abordar, además de los procesos de construcción del cuerpo, las manifestaciones de esta potencia vital en el territorio, que es el cuerpo de la Madre universal. La sangre circula conectando opuestos a la vez que se compone de fuerzas opuestas, de manera que debe ser entendida a partir de movimientos oscilatorios y no de atributos estáticos. La sangre menstrual tiene una potencia que debe ser mediada por el mamo, la mujer y potencias del territorio.

Palabras clave: sangre; Iku; cuerpo; territorio; menstruación. 


\section{Glossário}

A'buru: "material" que carrega pensamentos e intenções. É entregue nos trabalhos tradicionais para alimentar e estabelecer uma relação com seres do território.

Anugwe: potência vital relacionada com pensamento, conhecimento, habilidade, capacidade e afetos.

Anugwe jina: Conjunto dos seres vitais que têm anugwe

Butisinu: ameaça causada por, e que gera derramamento de sangue, dor e pode provocar a morte.

Chundwa: Pai principal, Pai do conhecimento. Também é o bico nevado mais alto da SNSM, chamado pelos não indígenas de bico Colón.

Duna: força “positiva”. Relacionada com terras altas, sol, homem, lado direito.

Gansigna: força "negativa". Potência muito poderosa que gera a vida, mas que precisa ser regulada para não virar um obstáculo que impeça ela. Relacionada com a terra, a lua, terras baixas, mulher, lado esquerdo.

Goraba: semente de terras quentes usada nos rituais das mulheres.

Gunseymake: primeira fase do ciclo vital, inclui a concepção, o parto e o ritual do Jwa Unkusi.

Je: agua

Jwa: Sangue. Tabaco.

Jwa Unkusi: ritual da primeira fase do ciclo vital. Em esse ritual, são harmonizadas as relações com todos os seres do cosmos, para o ingresso do novo ser no tecido de trocas coletivas. Nesse ritual, a pessoa recebe seu nome.

Jwa vica: coração.

Kankurwa: casa cerimonial

Kunsamu: Conhecimentos ancestrais.

Mamo: Autoridade tradicional. Sabedores dos conhecimentos ancestrais.

Murumsama: materialização da existência oculta da pessoa, do seu anugwe. Outro corpo.

Munseymake: Fase do ciclo vital relacionado com o desenvolvimento da semente. É o ritual da menarca.

Sein zare: pensamento da mãe universal. Existência potencial do cosmos.

Tikun: existência de um ser no pensamento da Mãe, no Sein zare. Tina: manifestação no mundo da existência em tikun.

Tutu: mochila tecida de algodão ou fique.

sangue, principalmente o sangue menstrual, usualmente é associado à fertilidade, à vitalidade, aos vínculos do parentesco, aos processos de construção de corpo e pessoa, e às diferenças que moldam as relações entre homens e mulheres, bem como suas atribuições na produção e reprodução (LÉVI-STRAUSS, 1981, VÍCTORA, 1991, FACHEL, 1994, BELAUNDE, 2005, ROSAS, 2019). Pretendo ressaltar que no caso do povo indígena Iku, da Serra Nevada de Santa Marta, Colômbia, a análise do sangue deve ir além dos corpos humanos e incluir sua manifestação no território, que segundo os Iku, e os outros povos indígenas da Serra Nevada, é o corpo da Mãe primigênia universal (REICHELDOLMATOFF, 1978, 1985, 1987, 1991; OROZCO, 1990; TAYLER, 1997; PATERNINA, 1999; OGT, 2012; ARENAS, 2016). Esse corpo-território é um tecido de 
relações entre os seres do cosmos, cuja vitalidade depende da troca de potências vitais, anugwe, entre os seres (OGT, 2012). Uma dessas potências é o jwa, o sangue. Para o povo Arhuaco, o jwa é a materialização da mais poderosa potência vital, que existe inicialmente no plano do invisível, o Seyn Zare, que segundo as narrativas míticas coletadas por Mora e Villafaña (2018) é o pensamento da Mãe universal. Essa potência tem uma força positiva, duna, e outra negativa, gansigna, pelas quais o sangue pode gerar a vida, mas também destruí-la. Essa potência vital também se materializa em outros elementos do território, como a água, je, que é a origem da vida para os Iku (TAYLER, 1997). Os mais de 30 rios que nascem nos nevados são as veias do corpo da Mãe (MORA E VILLAFAÑA, 2018), sendo que eles podem levar água duna ou água gansigna. Podem alimentar os seres do território ou causar doenças (YOSOKWI, 2015).

Em outros contextos etnográficos, a capacidade do sangue de causar dano tem sido relacionada com um potencial de perigo e contaminação (DOUGLAS, [1966] 2007, LÉVI-STRAUSS, 1981), mas sua relação com a fertilidade e a reprodução faz com que o sangue relacione forças opostas, gerando uma "antinomia fundamental" entre o sangue que gera vida e o sangue da morte (HÉRITIER, 2012: 122 apud ROSAS, 2019: 84). No caso Iku, a coexistência dessas forças é o princípio vital da existência; é necessário um movimento contínuo de oscilação entre opostos para que a vida possa emergir. Os seres estabelecem vínculos trocando potências vitais, o que permite a vitalidade do território e deles mesmos. Essas trocas devem ser reguladas para controlar a tendência à potência negativa, que segundo meus interlocutores, é mais forte (HORTA, 2020); como já referido por Uribe (1998), a existência para os povos da Serra Nevada de Santa Marta tem uma inerente tendência ao caos.

Abordar a manifestação do sangue no território permite entrever a sua capacidade para estabelecer vínculos entre seres diferentes, tecendo o território e regulando as forças opostas que compõem tanto o sangue quanto o território. Neste trabalho discorrerei sobre essa relação do sangue com o território, em relação ao processo de munseymake, fase do ciclo vital Iku relacionada com a menarca. As reflexões que aqui apresento foram suscitadas na minha pesquisa de doutorado, a qual surgiu a partir de uma inquietude sobre a territorialidade indígena, que, no caso Iku, está relacionada com as práticas de construção de corpo e pessoa. Apesar de não ser parte do objetivo central de dita investigação, o sangue se revelou como uma questão importante que articula as relações entre corpos e território, que entendo como agrupamentos similares de relações vitais em escalas diferentes, interligadas e interdependentes. Este trabalho é uma primeira aproximação do papel do sangue como articulador desses agrupamentos.

Para começar, referirei algumas questões gerais sobre a Serra Nevada de Santa Marta e os Iku. Situarei minha pesquisa nesse marco e mencionarei questões teóricas e metodológicas que têm conduzido a minha análise. A seguir, vou falar do território Iku, da água e, finalmente, vou me referir ao munseymake.

\section{Os Iku, a Serra Nevada e o corpo}

Os Iku, Ika ou Arhuaco constituem um dos quatro povos indígenas que moram na Serra Nevada de Santa Marta (doravante SNSM), ao norte da Colômbia, no litoral caribe. Segundo Uribe (1998), os Iku, os Kogui, os Wiwa e os Kankuamo constituem uma grande sociedade que compartilha uma origem e princípios cosmológicos, o que compõe o que eles chamam de "Lei da Mãe", "Lei de Sé", ou "Lei da origem". Segundo lideranças e autoridades tradicionais indígenas, a Lei de Sé 
é o pensamento da Mãe universal (Sein zare), que se expressa no território, e que estrutura e regula as relações entre os seres do cosmos (OGT, 2012). Os mamos ${ }^{2}$ são as pessoas -no caso Iku, geralmente homens- que recebem um processo de socialização e educação diferenciada para interpretar, para "ler" (URIBE, 1998) a Lei de Sé que está plasmada no território. Os mamos são os sabedores, autoridades tradicionais que a partir de seus conhecimentos ancestrais, regulam as relações entre os seres do cosmos (ARENAS, 2016).

Os quatro povos têm pequenas diferenças entre si, algumas delas relacionadas com os matizes dos processos históricos da colonização da SNSM no território de cada povo (Uribe, 1998). Os quatro povos são considerados seminômades, com um padrão de mobilidade vertical que responde tanto a motivações econômicas (REICHEL-DOLMATOFF, 1985; URIBE, 1988) como cosmológicas e rituais (VILLEGAS, 1999; CAYÓN, 2003; ARENAS, 2016; HORTA, 2020). Embora cada um desses povos tenha uma língua diferente, os quatro fazem parte da família linguística chibcha. Os Iku habitam principalmente a zona sul ocidente da SNSM, e sua língua é Ikun.

A SNSM é uma das montanhas litorâneas mais altas do mundo, pois só 40 quilômetros separam as praias dos bicos nevados de mais de 5700 metros. A SNSM é a principal fonte hídrica da região, e é uma área de desenvolvimento importante para o país que atrai megaprojetos, o que tem gerado conflitos com os povos indígenas, os quais defendem seu território (RODRIGUEZ, 2014). Esses conflitos também têm motivado processos de organização política dos povos, de forma tanto independente, como conjunta. Os Iku tem mais de 100 anos interagindo com o Estado nacional ${ }^{3}$.

Em fevereiro de 2016, fui convidada pela Confederación Indígena Tayrona CIT, a organização indígena do povo Arhuaco ou Iku, para focar minha pesquisa de doutorado em antropologia social no conflito da ocupação do morro Inarwa pelo exército colombiano. O convite respondeu a relações de confiança e respeito mútuo com algumas lideranças Iku iniciadas no ano de 2011, quando comecei a trabalhar na SNSM, sobre temas de conservação e ordenamento do território ${ }^{4}$.

A CIT tinha estabelecido uma ação de Tutela ${ }^{5}$ que teve como resultado a sentença da Corte Constitucional T- o05 de 2016. Nessa sentença, a Corte reconheceu que a ocupação do exército e a instalação de antenas de comunicações no Inarwa, tinha causado um "impacto cultural de dano imaterial”, e ordenou iniciar um processo de diálogo entre demandados e demandantes para caracterizar a afetação e concertar medidas de reparação e compensação. Minha pesquisa se desenvolveria paralela ao processo jurídico. Em um acordo, que chamamos de "apoio mútuo", combinamos com a diretiva da CIT que minha pesquisa se focaria no "sentido cultural" do Inarwa e nas práticas relacionadas com ele. Na experiência da CIT, investigações acadêmicas, principalmente de pós-graduação, têm aportado recursos importantes que são considerados pelas cortes nos processos

\footnotetext{
${ }^{2}$ O Ikun, a língua dos Iku, não tem uma escrita unificada. É possível encontrar referências aos sabedores dos povos da Serra escritas como mama, mamu, mamu, mamë, mamo. Usarei a palavra mamo, que é a mais comum nos escritos indígenas. As outras palavras em ikun estão escritas seguindo sugestões feitas pelo professor Iku Faustino Torres, a quem agradeço o apoio.

3 Sobre os processos organizativos da SNSM, consultar ULLOA, 2004. Sobre as particularidades do processo organizativo Iku, consultar FRIEDE, 1963, TORRES SOLÍS, 2004.

4 Nos anos 2011 e 2012, trabalhei com Parques Nacionales Naturales de Colombia, assessorando, entre outras áreas de conservação no Caribe, o Parque Nacional Natural Sierra Nevada de Santa Marta, para conciliar com as autoridades indígenas o ordenamento e a conservação em territórios indígenas sobrepostos com áreas de conservação ambiental. Entre os anos 2013 e 2015, trabalhei com os Kogui, para minha dissertação de mestrado em Antropologia social.

5 Mecanismo especial de proteção de direitos, criado na Constituição Nacional de 1991.
} 
jurídicos ${ }^{6}$. Com o apoio da CIT, a autorização das autoridades locais e a aprovação dos Iku em assembleia em Nabusímake, a capital do território Iku, fiz trabalho de campo durante 13 meses, distribuídos nos anos 2016, 2017 e 2018, principalmente em Nabusímake. Comecei participando em reuniões de debates sobre a sentença, com lideranças e mamos. Nessas reuniões, os mamos argumentaram que Inarwa estava fraco e doente, pois não tinha sido "alimentado" com os "trabalhos tradicionais" desde a ocupação do exército em 1962. Sua debilidade afetava a circulação de anugwe, potência vital entendida como pensamento, conhecimento e habilidade que deve circular entre os seres do cosmos para existir e permitir a existência do universo. Assim, a fraqueza de Inarwa afetava todo o território, o que, para os povos da SNSM, é um tecido de relações entre seres (OGT, 2012). Para os mamos, as relações com Inarwa deviam ser reestabelecidas por meio dos "trabalhos tradicionais", trocas de elementos e substâncias, e manifestações das forças vitais, anugwes, que compõem as pessoas e o território (FERRO, 2012, ARENAS, 2016, HORTA, 2020). São essas relações de trocas as que "tecem" o território, relações nas quais é possível a existência comum.

Segundo os mamos, o Inarwa é um anugwe jina, um ser vital de pensamento e conhecimento. A vitalidade e a função de cada ser no mundo dependem do seu anugwe, dos conhecimentos, pensamentos e habilidades. Em ikun, In significa milho, e rwa é morro; Inarwa é o morro do milho, seu anugwe está relacionado com o cuidado e a regulação do milho, das sementes e dos alimentos. Para os Iku, as pessoas são milho; o milho é uma réplica das pessoas (TAYLER, 1997). Nesse sentido, o anugwe do Inarwa está relacionado com a regulação da existência, da sexualidade e das relações entre os seres do cosmos. Inarwa é o ser "dono" do conhecimento das etapas da existência de todo ser (HORTA, 2020). Quando entendi essa relação, comecei a indagar pelas fases do ciclo vital com as mulheres com as quais já tinha amizade. No texto da tese, foquei-me na primeira fase, o gunsyemake. Neste trabalho pretendo abordar o momento da menarca, o munseymake.

Com o intuito de responder ao desafio de entender ao Inarwa como um anugwe jina, um ser vital de pensamento, dialogo com reflexões pós-estruturalistas que fazem parte da chamada "virada ontológica". A análise que aqui apresento continua situada nesse campo teórico. Conforme vários autores têm sugerido, por exemplo, Dos Santos e Tola (2016), a virada ontológica constitui um campo heterogêneo de enfoques diversos que questionam a universalização dos traços dominantes da racionalidade moderna eurocêntrica, que se fundamenta na separação entre natureza e cultura, e procuram reconhecer outras configurações da existência, enfatizando o caráter relacional, composto e processual da sociabilidade. Considero que, antes que modelos teóricos ou tipologias ontológicas, tratam-se de ferramentas reflexivas e teóricas que podem ajudar no entendimento de relações entre seres de mundos diversos. Nesse sentido, De la Cadena (DE LA CADENA; RISØR; FELDMAN, 2018) usa o termo "abertura ontológica” para essas reflexões teóricas que permitem abrir conceitos e ir além das limitações das dicotomias modernas derivadas do binômio natureza/cultura. Por exemplo, é possível romper a dicotomia sujeito-objeto e questionar o entendimento do território como um objeto nessa divisão e, inclusive, como outro ser em uma relação. $\mathrm{O}$ território, argumenta De la Cadena (2015), a partir do caso dos Andes peruanos, pode ser pensado como um evento que é construído nas relações, que parece ser o caso também da Serra Nevada de Santa Marta. Tratam-se de contextos nos

6 Por exemplo, as teses de Duque Cañas (2009) y Vargas (2004), aportaram argumentos sobre o território indígena, que foram incorporados na sentença da Corte Constitucional T-849 de 2014. 
quais existe uma continuidade ontológica entre seres interdependentes que se afetam e se constituem mutuamente.

É o caso dos Iku, no qual o território é definido por eles mesmos como um tecido de relações, um sistema em que fluem potências vitais, circulação da qual depende a vida no território, um ser vital composto por outros seres vitais (OGT, 2012). Quer dizer que tanto o território quanto os seres que o compõem são possíveis nas relações que estabelecem.

Por outro lado, o trabalho de Seeger, da Matta e Viveiros de Castro (1979) chamou a atenção sobre a centralidade do corpo em vários contextos etnográficos da América do Sul. Os autores argumentaram que o entendimento do corpo, como um substrato biológico no qual são projetadas identidades e papéis sociais, não é universal. A evidência etnográfica sugeria que o corpo é uma matriz simbólica que articula questões sociais e cosmológicas. Assim, a corporalidade e os processos de construção de pessoas seriam os eixos organizadores dos universos indígenas sul-americanos. Neste contexto, é possível pensar o corpo não como algo dado, senão em constante construção, incentivada pelo intercâmbio de propriedades com outros seres do cosmos, fazendo parte de campos relacionais (SANTOS GRANERO, 2012). Alguns autores que trabalharam neste campo de análise, são Taylor (1996), McCallum (1998), Belaunde (2005), Vilaça (2005) e Tola (2012), entre outros.

No caso Iku, os corpos têm uma estrutura que é replicada na casa cerimonial, a Kankurwa, nas montanhas, na Serra, e no cosmos, estabelecendo uma "cadeia de relações" entre diferentes níveis que se contêm mutuamente (REICHEL-DOLMATOFF, 1975, 1978, 1985, 1987, 1991; OROZCO, 1990; PATERNINA, 1999; TAYLER, 1997; URIBE, 1998; CAYÓN, 2003; ARENAS, 2016). Trata-se de uma estrutura atravessada por uma divisão horizontal que separa a parte superior, relacionada com a potência duna "positiva", da parte inferior, relacionada com a potência gansigna, "negativa". O mais importante é que cada um destes níveis (corpo, kankurwa, serra, cosmos) é entendido como um útero que contém os conhecimentos e princípios vitais que geram a existência; é nesse sentido potencial que cada nível contém tudo o que existe no mundo. Nessa lógica, é razoável pensar que o corpo, a serra e o cosmos têm relações fractais, ou integrais (WAGNER, 1991), nas quais não é possível estabelecer limites entre cada uma das entidades relacionadas, pois se gestam e se compõem entre si. Seriam segmentos de uma estrutura que pode se replicar ao infinito, respondendo assim ao princípio de autossimilitude dos fractais (BRAUN, 2003). Cada entidade mencionada poderia ser pensada como um agrupamento de relações vitais em escalas diferentes, mas interligadas. Importante salientar que a estrutura que é replicada, vincula forças opostas: duna e gansigna, assim sendo, o padrão autossimilar não implica homogeneidade, dado que refere uma unidade múltipla (HORTA, 2020).

\section{A dualidade da existência}

A Lei de Sé ou Lei da Origem, não é um agrupamento de normas e regras. A Lei de Sé refere-se ao pensamento da Mãe universal, o Sein Zare, como potencial de existência, conforme me foi dito pelo antropólogo e professor Iku, Faustino Torres. A Lei de Sé faz alusão aos princípios cosmológicos que explicam a origem do universo, e a regulação dos seres existentes. Está relacionada com os conhecimentos ancestrais, kunsamu, que permitem "ler" no território a Lei de Sé. Nenhum mamo pode aceder à totalidade do Sein zare, ou da Lei de Sé. Cada mamo tem conhecimentos específicos, conforme sua própria experiência, que aportam 
para o entendimento da complexidade (TAYLER, 1997); é por isso que as decisões são tomadas por grupos de mamos que trazem seus conhecimentos, o que implica uma atualização epistemológica constante (ARENAS, 2016).

Embora, em princípio, os kunsamu sejam conhecimentos especializados dos mamos, as relações com os seres do cosmos fazem parte da experiência cotidiana com o território; por conseguinte, e como me foi dito por Jeremias Torres, reconhecido líder Iku, todas as pessoas têm algo de mamos. A lei de Sé e os Kunsamu, até certo ponto, são conhecimentos compartilhados que estruturam as diversas práticas das pessoas. É importante salientar que a Lei de Sé, não é estática, pois os princípios cosmológicos são atualizados nas dinâmicas de relacionamento (HORTA, 2014, 2020). Como foi referido por Sahlins (1997), as questões cosmológicas podem se relacionar com os contextos pragmáticos atualizando os sentidos tradicionais.

Segundo as narrativas da origem, tudo o que existe, já existia como gente, mas sem forma, na escuridão do Sein Zare o pensamento da Mãe. O termo Sein Zare, vem de Sey, que se refere à escuridão, a cor preta, a potência gansigna que tem a força para gerar vida. $\mathrm{O}$ universo foi gerado com a ajuda de pais e mães ancestrais, criados pela Mãe universal, sendo que os primeiros foram Serankwa e Seynekun, responsáveis pela materialização do universo. Conforme as narrativas, míticas coletadas por Mora y Villafaña (2018):

La unión de Serankwa e Seynekun, de lo masculino y lo femenino, de lo positivo y lo negativo, del dia y la noche, del sol y de la luna, dio origen a todas las autoridades espirituales que gobiernan el mundo material. (MORA e VILLAFAÑA, 2018: 38)

Assim, a relação dos opostos gerou a vida. Reichel-Dolmatoff (1991) notou em suas pesquisas entre 1946 e 1966, que o universo dos Iku é estruturado a partir de forças opostas. Desde a origem do universo, possível pela união entre o feminino e o masculino, se desprendem as potências duna e gansigna, traduzidas como "positiva" e "negativa", as quais estruturam uma série de opostos tais como sol/lua, acima/abaixo, frio/quente, esquerda/direita etc. Essas potências, no caso Iku, estabelecem uma relação de complementariedade e continuidade. Ao falar de potência, refiro-me a uma força que é capaz de gerar algo, de produzir um efeito. A tradução que os mesmos Iku fazem das potências duna e gansigna como "positivo" e "negativo", é problemática, porque nos situa em categorias de valor absolutas e excludentes, que se afastam do sentido complementário que elas têm no universo Iku. Assim, Jeremias Torres, me explicou que nada é absolutamente gansigna nem absolutamente duna. Tudo está composto por uma parte duna e outra gansigna que, ao ser abordadas de perto, apresentarão a mesma bifurcação. Quer dizer que é um padrão dual, que é repetido em diferente escala, à maneira de um fractal que replica-se ao infinito. Segundo Jeremías, o feminino se relaciona com a força gansigna, a lua, a terra, as partes baixas do território, e a parte baixa do corpo, espaços relacionados por sua vez, com o calor e a potência sexual. Isso não quer dizer que essas cadeias de relações sejam "negativas", no sentido de "ruins". Trata-se de forças muito poderosas que devem ser reguladas, já que se comandar o movimento da existência, podem virar um obstáculo para ela. A sexualidade, por exemplo, é a força da que depende a existência, mas se a semente vital é dispersada sem controle, pode fertilizar forças negativas. Segundo Reichel-Dolmatoff, grande parte das práticas dos povos da SNSM, têm a ver com a regulação da sexualidade $(1947,1985,1991)$. Ángel e Emilio Izquierdo, filhos do mamo Gregorio Izquierdo, me comentaram que o duna e o gansigna, fazem parte da unidade, mas o gansigna deve ser regulado para que sua força apoie o movimento para cima, para o duna, respondendo ao ideal dos Iku que é avançar em 
direção a Chundwa, o pai do conhecimento, como explica Tayler (1997). Caso contrário, a existência mesma estará em risco. No mundo escuro, relacionado com a origem, o pensamento da Mãe, é onde surge a possibilidade de existência, mas sendo levada para a luz, para cima. Assim, a regulação da força gansigna é realizada por médio do vínculo com seu oposto complementar, vinculo que permite a circulação de potências vitais, e a construção do tecido vital que é o território.

Os seres que compõem o território, devem se relacionar com seus opostos complementares, por exemplo, terras altas com as terras baixas, homem com mulher, etc. Os vínculos entre os seres se estabelecem através de trocas de elementos que materializam potências vitais, que são entendidas como alimentos ou $a^{\prime} b u-$ rus. Esses elementos podem ser comida, conhecimentos, palavras, sentimentos, etc. As trocas devem ser recíprocas e podem acontecer de várias formas: pelos ciclos da natureza, por exemplo, pela água dos nevados que desce pelas lagoas e rios até chegar no mar e, a partir daí, volta nas nuvens e na chuva nas partes altas. Também acontecem nos intercâmbios recíprocos cotidianos, conhecidos como makruma, trocas que ocorrem nas visitas, nos cumprimentos, nas conversas, nas quais circula o que cada pessoa pode produzir, a sua própria vitalidade (FERRO, 2012). As conexões também são feitas pelos "trabalhos tradicionais", nos quais se faz um intercâmbio de anugwe, dando a cada ser o que ele precisa, seu complemento. Os "trabalhos tradicionais" também são chamados de "pagamentos", pois são uma retribuição aos "donos" pelo usufruto da sua criação, sendo sempre uma questão de mão dupla. Nos processos de trocas, os seres do cosmos são afetados e construídos. O fundamento da existência Iku é a interdependência, para existir é preciso estabelecer relações recíprocas, intercambiar sustento, anugwe (ARENAS, 2016; HORTA, 2020). Porém, as relações entre os seres do cosmos propendem ao caos, e podem ser perigosas, é por isso que devem ser mediadas pelos mamos, no sentido de Latour (2012). Isso quer dizer que os mamos intervêm nas trocas com seus próprios anugwes, a fim de equilibrar o $a^{\prime}$ buru entregado e a relação estabelecida na transação, sendo que eles também são afetados pelas forças reguladas.

O anugwe, como já foi dito, é potência vital relacionada com conhecimentos, habilidades e pensamentos. O anugwe é construído e corporificado nas relações com os seres do cosmos, nos trabalhos tradicionais, nos processos específicos de educação dos mamos, nos rituais do ciclo vital, e na experiência do território, a partir das relações estabelecidas com os donos dos conhecimentos e pensamentos, mediados pelos mamos. O anugwe é alimento, pois é uma potência vital que é corporizada, sustentando o corpo. Assim, a existência da pessoa é construída nas relações que estabelece com outros seres. Nesse sentido é possível estabelecer um vínculo com as reflexões de M. Strathern sobre a noção de pessoa na Melanésia. Segundo Strathern (2006), desde a tradição britânica na antropologia, a noção de pessoa está relacionada com a noção de "individuo", como unidade fechada e irredutível da sociedade, cujas relações são secundárias, no sentido que são exterioridades. Strathern questiona a universalidade dessa noção, notando que na Melanésia, as pessoas são entidades abertas, atravessadas e constituídas internamente pelas relações que estabelecem. Nesse sentido, as pessoas não seriam "indivíduos”, mas seres “divíduos”, termo que toma de Marriot (1976 apud STRATHERN, 2006) para referir seres que poderiam se dividir nas relações que os compõem. Entendendo as pessoas como seres compostos, Strathern traz uma noção de pessoa que articula o singular e o plural como categorias não excludentes. No caso dos Iku, as trocas recíprocas de anugwe como o makruma e os trabalhos 
tradicionais, os seres recebem e entregam potencias vitais que são incorporados na própria existência, construindo corpos e pessoas (ARENAS, 2016), como também constroem o território, tecido vital que é possível graças à circulação de $a n u-$ gwe.

O sangue é uma manifestação do anugwe dos seres. Conforme foi mencionado no início, o sangue é potência que gera a vida. Relacionada com a fertilidade, essa potência manifesta-se no corpo-território em outras substâncias ou elementos, tais como a água. Entendo que trata-se de uma mesma potência vital, que tem diferentes manifestações no mundo, como sugeriu também Arenas (2016). O professor Iku Faustino Torres, me explicou que a existência de todos os seres do cosmos tem dois planos: o tikun, usualmente traduzido como "em espírito" ou "em pensamento", é a existência em Sein zare. A vitalidade dos seres depende desse plano, no qual encontra-se o anugwe, a potência vital de cada ser. O Anugwe é pensamento, a partir do qual os seres afetam e são afetados por outros seres. Tudo o que tem vida, tem anugwe, que está relacionado com sua função no mundo. Essa potência vital se materializa em objetos ou elementos do corpo e do território. Assim, o sangue, jwa, é uma das "materializações" do anugwe da pessoa. O mesmo princípio vital, estaria manifestado na água, sendo o sangue do território. Com isso, teríamos o outro plano, o estado chamado de tina, que é a manifestação da existência usualmente traduzida como "material". As traduções dos termos tikun como espiritual, e tina como material, aludem à dicotomia material/imaterial como opostos excludentes, que não é o caso no universo Iku. Faustino, e alguns mamos, mencionaram que tudo o que existe no mundo, é uma semente em tikum que vem a se manifestar em tina. Ou seja, tina existe porque existe em tikum. Tina e tikun referem uma correlação vital, de interdependência, um princípio de continuidade e unidade ontológica. Arenas (2016) traduz tikun como invisível e tina como visível, mas esses termos, não conseguem manifestar a correlação vital que estou assinalando aqui. Dada a limitação da tradução, continuarei usando as categorias nativas.

Assim sendo, os anugwe tem manifestações tina, que podem ser múltiplas. Os anugwe podem se manifestar tanto em substâncias no corpo, como em elementos ou substâncias do corpo-território, sendo que, como já foi dito, o corpo e o território são escalas diferentes, vinculadas, de agrupamentos de relaciones, entre as quais circulam potencias vitais. O sangue e a água, são manifestações do anugwe que gera vida. Do mesmo modo, os anugwe que podem regular a força gansigna do sangue, tem manifestações no território, em elementos ou objetos que são usados nos trabalhos tradicionais. Assim, nos rituais, a pessoa recebe um objeto que materializa a capacidade/pensamento ou conhecimento recebido. Os objetos, assim como no caso dos Mbya Guarani (BAPTISTA DA SILVA, 2013), incorporam potências, conhecimentos, e materializam as relações estabelecidas, configurando ao ser, e às redes a que este pertence. Para os Iku, esses objetos constituem o murumsama da pessoa, o que tem sido interpretado como um "diploma" que certifica que a pessoa tem esse anugwe (ARENAS, 2016). Porém, Faustino Torres tem me dito que se trata da materialização da existência invisível ou oculta, murzm, da pessoa. Nesse sentido, é um outro corpo, um alter ego. É a incorporação de anugwe, que modifica a existência, a função no mundo, as potências que constroem a pessoa. Vou retomar o murumsama posteriormente.

A partir de vários contextos etnográficos na Amazônia, Belaunde (2005: 38) observa que é comum que "el pensamento se hace cuerpo en la sangre", veiculando conhecimentos, emoções e afetos, questionando a dualidade cartesiana que 
separa corpo e mente. No caso Iku, o pensamento se corporifica também em elementos do corpo-território, que vão compor o murumsama da pessoa, seu outro corpo.

\section{O sangue do corpo da Mãe universal}

Segundo Tayler, para os Iku, a vida surge da água (1997). O anugwe primordial da água é chamado de anugwe anisi, e faz referência a sua pureza. Esse anugwe está nas lagoas dos nevados. Sua força deve estar presente nos partos para que a vida possa fluir, segundo foi falado por mamo Vicencio. A água (je) deve circular para levar alimento, pensamento, e limpar aos seres que compõem o tecido vital. Desde as lagoas dos nevados, os rios descem nas montanhas e morros até chegar no mar. Depois a água retorna às montanhas, e se limpa para descer de novo, conectando as partes altas com as partes baixas. Os rios percorrem o território e conectam aos seres que o compõem. A mãe dessas águas é Naboba, que também é a mãe do tecido (TAYLER, 1997), pois a água, tece relações entre seres. Foi por isso que nós profissionais que estávamos articulados ao processo do Inarwa, fizemos um "trabalho tradicional" que incluiu depositar nossas intenções e compromisso em algodões que entregamos ao mamo, e mergulhar no rio Ariguani, que nasce no Inarwa, para nos conectar com sua força. Como observa Stengers (2008), conectar é reconhecer a existência do outro.

As lagoas são mães, e a água é relacionada com a força gansigna, elas surgem nas terras altas, na parte duna do território, no frio. Existem águas positivas, je duna, são as águas que correm, que estão saudáveis e levam alimento. A chuva jewvi, pode ser positiva, se não é muito forte e não prejudicar os cultivos. As águas gansigna não são prejudiciais per se. O mamo David Villafaña, narra no documentário Naboba. Visión ancestral del agua del pueblo Arhuaco (YOSOKWI, 2015), que as águas gansigna, "negativas", afugentam as doenças, por meio do banho do corpo, pois levam a sujeira junto. Essas águas não podem ser bebidas, nesse caso, podem sim fazer dano. A mediação do mamo é seu anugwe, é importante para que essas águas possam limpar os corpos. Da mesma forma, o anguwe do mamo deve ser forte, adverte mamo David, caso contrário, ele será afetado negativamente pela água. A água do mar, conforme contou-me mamo Miguel é a união da potência sexual masculina e feminina, é por isso que a vida vem do mar. Tudo o que existe no mundo, existe também no corpo: "temos a lei no corpo", falou para mim Mamo Miguel.

A vitalidade do corpo-território da SNSM, depende da circulação continua e fluida das diferentes águas, sendo que o represamento implica doença. As águas devem percorrer o corpo-território, conectando-o, cumprindo sua função e regulando suas forças. A interdependência dos seres, e a integralidade da SNSM, construída na fluidez de potências vitais, têm sido argumentos centrais dos povos indígenas na defesa da SNSM contra megaprojetos como represas e portos, que afetam a circulação no tecido vital (ZHIGONESHI, 2011; RODRIGUEZ, 2014; HORTA, 2015)

\section{O Munseymake}

A vida tem quatro fases, nas quais o ser troca com outros seres do cosmos potências vitais, fluidos e anugwe, correspondentes com cada fase. É assim que se estabelecem as redes de afetação e construção de corpos e pessoas neste cole- 
tivo (LATOUR, 2007), anugwe jina, formado por seres humanos e extra-humanos. Usualmente se diz que a primeira etapa da vida é o Gunseymake, que inclui a concepção, o nascimento e o ritual de entrega do nome. Mas, para algumas pessoas, a vida começa com o cuidado do jwa feminino para a reprodução. Vou me referir a algumas questões do ritual dessa etapa da vida das mulheres, o munseymake.

A menstruação das mulheres da SNSM não tem sido muito comentada na etnologia indígena. Reichel-Dolmatoff (1985) faz algumas referências à menarca, no marco dos ciclos de vida dos Kogui. Menciona que o sangue é recolhido e entregue a Heisei, entidade da morte para os Kogui. Segundo o autor (1985: 197), a vida das meninas continua sem mudanças e sem aprendizado nenhum. Possivelmente essa afirmação corresponde à centralidade das atividades dos mamos e dos homens para o trabalho do Reichel-Dolmatoff, bem como sua pouca proximidade com as atividades femininas. Sobre os Iku, Reichel-Dolmatoff menciona que o sangue da menarca deve ser recolhido e entregue como oferenda aos que ele chama de "deuses". O autor traz o testemunho de uma mulher que não recolheu seu primeiro sangue, o que para ela foi a causa das mortes de três filhos nos partos (1991: 68). Em suma, o que refere Reichel-Dolmatoff a respeito do sangue menstrual é sua relação com a morte. Por sua parte, Arenas (2016) comenta algumas questões gerais do ritual da primeira menstruação, o "banho" feminino e a importância do sangue como potência vital, estabelecendo bases relevantes para aprofundar as caraterísticas e capacidades do jwa.

A etapa da primeira menstruação nas meninas é chamada de Munseymake. Segundo o professor Faustino, Mun significa doce, que é atraente, mas também aquilo que é muito perigoso, pois pode "manchar". Seymake, por sua vez, se refere à inocência, que ainda não teve relações sexuais. Quer dizer que é a etapa em que a mulher tem o seu corpo tanto a potência para dar vida como para destruíla, em estado puro, em virtude da ausência de contato sexual e das potências que ele implica. A potência vital é composta por duas forças que devem ser equilibradas. Para explicar essa fase, o professor Faustino diz que é como uma flor que se abre, linda, atraente, cheirosa, mas muito perigosa. O sangue menstrual tem a força duna e a força gansigna. As mulheres menstruadas levam essas potências no corpo e, por isso, não devem entrar nas hortas, pois podem murchar as plantas. O potencial gansigna deve ser limpo e equilibrado, mas não pode ser eliminado, pois a vida é gerada no equilíbrio dessas duas forças complementares.

Para esse equilíbrio, é realizado o ritual do "banho da menstruação", que inclui 9 dias de isolamento antes do banho. A menina, nas suas primeiras quatro menstruações, precisa ficar isolada, sem tomar banho, sem pegar sol e sem conversar com homens. Em alguns casos, o isolamento e o banho são feitos só na primeira menstruação. A menina só deve conversar com as mulheres da sua família, fiar algodão, tecer mochila, chamada de tutu 7 e cultivar pensamentos positivos sobre a vida que vai experimentar como mulher. Foi assim na experiência de Seykúmake ${ }^{8}$, uma amiga Iku de 38 anos que cresceu em um assentamento perto de Nabusímake. Ela lembra que teve que ficar com as mesmas roupas durante esses dias e que foi muito difícil para ela ter pensamentos positivos, pois não se sentia confortável. Por isso, quando sua filha teve seu "banho de menstruação”, Seykúmake pediu permissão do mamo para que a filha trocasse as roupas, que deviam ser lavadas longe do rio.

7 Tecer mochila é uma atividade exclusiva das mulheres. A mochila iku ou arhuaca tem relação com a origem cosmológica, como será comentado mais adiante. A mochila se tornou um artesanato reconhecido e valorizado no território nacional. Ver por exemplo: https://www.lamochilaarhuaca.com.

${ }^{8}$ Seykúmake é o nome que ela escolheu para ser nomeada nos meus trabalhos. Ela prefere resguardar sua identidade. 
Durante esses dias, é preciso manter uma dieta sem sal e, em alguns casos, há outras restrições: por exemplo, na experiência de Plácida, se a menina quer cuidar e criar animais, deve evitar comer carne nesses dias para que os animais não fiquem magoados e não fujam dela. As restrições do sal e dos raios de sol estão relacionadas com as potências tikun desses elementos concernentes à fertilidade: os raios de sol são a potência que fertiliza a terra, enquanto o sal possui a potência fertilizadora do sêmen, presente também na água do mar. A menina terá de evitar elementos com potências fortes que possam entrar em conflito com a força de afetação que traz o sangue, que é inerente à capacidade de "manchar", impregnar de cor, sendo que as cores implicam forças e capacidades, como argumentarei posteriormente.

A menina, com ajuda de um mamo, precisa aprender como equilibrar essa força, para evitar que ela afete negativamente aos seres que entrem em contato com a menina. O conceito de butisinu é central nesse momento da vida. O butisinu, conforme me explicaram mamo Tobias Torres, mamo Miguel Niño e o professor Faustino, é uma força violenta que pode ser, ao mesmo tempo causa e consequência de derramamento de sangue, agressão, dor e morte. O butisinu está presente nas mortes violentas ou quando os morros, mamos poderosos, são destruídos, por exemplo, pela mineração. Essas situações que violentam o corpo-território da Mãe universal geram morte, doenças e acidentes violentos no território. Quando uma mulher está menstruada, ela leva no seu corpo essa potência do butisinu, que pode causar ou intensificar uma situação de violência. Por exemplo, se alguém é mordido por uma cobra e a mulher se aproximar para olhar, a situação da vítima poderia piorar até morrer. A força negativa do sangue afeta o anugwe dos seres que entram em contato com a mulher menstruada, ficando vulneráveis frente ao butisinu. É por isso que as mulheres menstruadas não devem entrar nas hortas, nem ter relações sexuais. O butisinu é o potencial perigoso do sangue da menstruação, do parto e da morte. As restrições do sal, dos raios do sol e das relações sexuais, já mencionadas, sendo forças da fertilidade, podem fecundar ou fortalecer à energia dominante, que no momento da menstruação, é o butisinu. Essas restrições, salvo à relacionada aos raios do sol, devem ser cumpridas também quando uma pessoa está doente ou quando tem alguma ameaça ou conflito no território. As potências relacionadas com a fertilidade afetam os corpos e o corpo-território como segmentos de um mesmo tecido vital.

Segundo as narrativas míticas, Serankwa pegou um fio desde Chundwa e a partir dele, começou a tecer movendo o fio em uma espiral que desce conectando os morros, lagoas e pedras, pais e mães mais antigos e poderosos. Assim formouse a SNSM, o corpo da Mãe universal (REICHEL-DOLMATOFF, 1978; OROZCO, 1990; GIRALDO JARAMILLO, 2010; MORA e VILLAFAÑA, 2018). O tecido da mochila recria essa espiral geradora de vida, mas no sentido contrário, de baixo para cima. A mochila é um útero que guarda os pensamentos das mulheres quando tecem (REICHEL-DOLMATOFF, 1985; TAYLER, 1997). Quando as meninas aprendem a tecer, só podem tecer nas cores branca e amarela. Quando menstruam, isto é, quando "mancham", elas podem começar a usar outras cores entendidas como mais fortes e perigosas, como vermelho, roxo, preto, verde etc. As cores estão relacionadas com potências e capacidades. Seykuinduva, uma menina de 12 anos, contou uma versão resumida da história da fertilidade da terra para mim:

Cuando todo era oscuro, la Madre tenía cuatro hijas: una blanca, otra amarilla, otra roja y otra negra. Serankwa pidió una de las hijas. Se casó con la blanca y crearon la tierra blanca. Serankwa plantó maíz en ella, pero no creció. Serankwa volvió con la madre y pidió otra hija. Se llevó a la amarilla, crearon la tierra amarilla, pero nada creció en ella. Los mismo pasó con la hija roja, que también fue infértil. Serankwa 
volvió y pidió a la hija negra, que no se la querían entregar, pero se la llevó y crearon la tierra negra. Ahí sembró maíz y esta vez sí creció. Así crearon a Seynekun, la madre de la tierra fértil.

Tudo o que existe passa por ciclos de quatro etapas para se concretizar. A vida tem quatro etapas, a fertilidade da terra e do sangue menstrual também. É por isso que alguns mamos recomendam que o processo de limpeza seja feito nas quatro primeiras menstruações. Para outros mamos, é suficiente limpar as quatro etapas na primeira menstruação. Conforme me explicou Seykúmake, as etapas e cores da criação da terra são as mesmas etapas e cores dos fluidos corporais na menstruação, sendo que cada cor carrega potências diferentes, que devem ser recolhidas e guardadas no primeiro ciclo menstrual, quando são mais fortes. Os primeiros fluidos, relacionados com as cores branca e amarela, são forças duna positivas, que têm o potencial de gerar vida, mas ainda não têm esta capacidade. É por isso que as meninas aprendem a tecer usando só essas cores, a saber, as cores que têm nos seus corpos. Com a menstruação vem as cores vermelha e preta, forças gansigna, capazes de causar butisinu, mas que também têm o poder da fertilidade. O sangue menstrual tem todas as cores, todas as potências do universo.

Durante os nove dias de isolamento da menina durante sua primeira menstruação, ela prepara os "materiais" ou a'burus para o trabalho tradicional, ou seja, os elementos que vai oferecer de alimento para os seres do cosmos, bem como os elementos que vão fazer parte de seu murzmsama, seu outro corpo, uma das manifestações em tina de sua existência em tikun. Para isso, conforme me foi dito por minhas interlocutoras, a menina fia algodão de diferentes cores, tingido por homens ${ }^{9}$, e recolhe em algodão selvagem seus pensamentos, segundo indicações do mamo, e um pouco dos seus fluidos. Esses "materiais" são mediados pelo anugwe do mamo, que pode regular o potencial butisinu do sangue e fortalecer sua capacidade de gerar vida. O mamo sabe como atualizar a criação do universo para que todos os seres, na ordem em que foram criados, sejam limpos e alimentados pela menina, aceitando sua nova condição como mulher "que mancha". Essa nova condição pressupõe a nova responsabilidade e a capacidade de ter relações sexuais, juntar-se com outro sangue e gerar vida. O reconhecimento do novo status da menina, por parte dos seres do cosmos, implica harmonia, no sentido que a ordem cosmológica é atualizada a partir de sua nova função, do seu anugwe atualizado, e da nova configuração de seu corpo, que ganhou o equilíbrio recebendo anugwe e alimentando com ele aos seres primigênios.

Os algodões com sangue e fluidos anteriores, depois de serem mediados pelo mamo, são repartidos. Um pouco deles será entregue a algum ser do território que precise ser alimentado pela força dessa menina. Outra parte ficará com o mamo e outra com a menina, sendo que essa é a mais forte proteção e fonte de defesa contra doenças e qualquer tipo de ameaça. A força da menina é incorporada pelo mamo, que é fortalecido pela potência desse sangue e pode utilizar essa força para se proteger e curar aos seres do território. A menina recebe uma nova capacidade e em troca, entrega seu sangue limpo e mediado pelo mamo, estabelecendo uma consubstancialidade entre ela, o mamo e o corpo-território. Como já foi dito, a substância carrega anugwe, que depois do rito é alimento, proteção e cura que circula entre alguns corpos. Seykúmake, descreve assim a força do seu primeiro sangue menstrual:

9 Conforme me foi explicado, como as mulheres já mancham, tingem com seus corpos, essa capacidade deve ser equilibrada, motivo pelo qual tingir o algodão é uma atividade masculina. 
(...) eso es una defensa propia que uno tiene en su mismo cuerpo, eso es para uno. Es un tesoro que te atranca inmediatamente cualquier problema: te vayan a matar, a secuestrar. O un familiar que esté en peligro de muerte, lo que fuese, ¿no? ese te ayuda a salvar, uno le puede ayudar a otra persona también.

Nesse sentido, o potencial butisinu do sangue é regulado e são fortalecidas as capacidades de gerar vida e curar, intensificando os valores benéficos do sangue. Mesmo assim, o potencial butisinu não desaparece, pois é parte constitutiva do sangue menstrual. A relação do sangue menstrual com a morte, referida por Reichel-Dolmatoff, não é de causa, visto que é uma força que oscila entre a vida e a morte. Tanto o butisinu como a capacidade de gerar vida não são estados ou atributos fixos do sangue menstrual, são capacidades potenciais que podem ser reguladas, graças à mediação do mamo, aos pensamentos e aos conhecimentos da mulher. O anugwe da mulher é corporificado tanto nas suas próprias substâncias como nos elementos do corpo-território usados no ritual, que compõem o murumsama feminino.

Os algodões com sangue que ficam com a menina fazem parte do seu $m u-$ rumsama. Alguns dos objetos que ela recebeu no ritual do jwa znktsi, são modificados no munseymake, pois sua existência e sua função no mundo mudam. Seu jwa já tem todas a cores, tem a capacidade de engendrar, tem as potências para se defender e os conhecimentos para se comportar e não gerar butisinu. Segundo Seykúmake, a semente de terras quentes chamada goraba, que ela tinha recebido, passaria a ser envolvida completamente nos fios de algodão tingidos de folhas e raízes das terras altas e frias, cores relacionados com potências duna, como chana (amarelo), urz (roxo claro) e kuguinu (vermelho claro). A menina também recebe uma concha de mar chamada muchurt. Quando tiver relações sexuais, esses objetos serão modificados novamente: a semente terá um pequeno buraco no centro, que será atravessado pelos fios de cores, tecendo e envolvendo a semente. Seu muchurz será trocado por outro que esteja mais aberto. Importante salientar que a semente e a concha provêm das partes baixas do corpo-território, relacionadas com a fertilidade e a potência gansigna. Assim como nos objetos do $m u-$ rzmsama, o outro corpo composto por objetos do corpo-território que materializam pensamentos e potência, a força gansigna é regulada, uma vez que é conectada com objetos que carregam forças duna. A mediação do mamo é central, pois a agência dos objetos não parece ser um atributo fixo, mas, sim, uma capacidade potencial que é ativada no campo relacional entre o mamo e seu anugwe, os objetos, o sangue, a mulher e seu anugwe.

A última parte do Munseymake é o banho. No final dos nove dias de isolamento, depois de ter acumulado os fluidos no seu corpo e neles, suas potências vitais, a menina vai com o mamo em uma pedra indicada por ele para lavar seu corpo e suas roupas. A água que vai lavar seu corpo é trazida por sua família de um manancial indicado pelo mamo, especificamente para essa menina. O mamo joga a água je duna nela, e depois vai embora para que ela termine de lavar seu corpo e suas roupas. É muito importante que o sangue menstrual nunca toque a água dos rios, pois sua força seria dispersada sem controle no território. Contrariamente às outras manifestações da potência do sangue, o sangue menstrual tem uma circulação restrita. No munseymake se estabelece um vínculo entre a menina, o mamo, e o território, entre os que circula anugwe, conhecimento/pensamento. O munseymake não tem um momento de coletividade que têm outros rituais como o jwa znkłsi, no qual é evidente o potencial do sangue para interligar seres.

No ritual do jwa unkusi, que é feito alguns meses depois do parto, o mamo tem que consultar no pensamento da Mãe universal o nome do bebê, segundo sua 
função no mundo. Os pais e o mamo, após terem realizado trabalhos tradicionais ao longo de uma semana, fazem uma cerimônia convidando aos amigos e familiares. Todos têm que oferecer alimento espiritual, sendo que assim se estabelece a rede de trocas de potências vitais do coletivo, na qual ingressa o novo ser. Em uma determinada parte do ritual, os convidados recebem tabaco, também chamado de jwa. Jwa significa sangue, mas como já mencionou Arenas (2016: 351), e conforme minha experiência, os Iku não afirmariam que o tabaco é sangue. Arenas conclui que sangue e tabaco são diferentes manifestações que partem de um mesmo princípio vital. Concordo com Arenas e também gostaria de acrescentar que a força desse princípio vital em tikun, manifestado em tina no tabaco e no sangue, é o movimento que se faz possível ao estabelecer vínculos entre seres, o que se manifesta com o uso do tabaco jwa no jwa znkusi. Angel Izquierdo, filho de um mamo, me convidou para participar de um jwa unkusi. Como convidados, recebemos tabaco branco, que devíamos colocar no peito do lado direito; e tabaco vermelho, que devíamos colocar no peito, do lado esquerdo. No final da cerimônia, entregamos esse tabaco para o mamo e os pais, que levaram esse e todos os materiais trabalhados para alimentar algum ser do cosmos, definido pelo mamo. A esse respeito, Angel me explicou que, em um primeiro nível, o tabaco é para que o novo ser não sinta pressão no peito quando subir uma montanha. Em um outro nível, é uma forma de materializar o fato de que se faz parte de uma mesma rede, na qual circulam anugwes, alimentos e potências vitais, dentre as quais encontra-se o jwa, o sangue, o tabaco. Vale a pena ressaltar que os dois tipos de tabaco, entregues às pessoas, devem ser colocados em cada lado do corpo, ecoando os princípios duplos, opostos, que compõem e dinamizam o mundo Iku, esquerda/direita, branco/vermelho, duna/gansigna, respectivamente. A tradução literal do jwa unkusi, segundo me foi explicado por Jeremias Torres, é "encher de sangue ao novo ser". Acredito que essa vitalidade, entregue para o novo ser, é a fluidez do anugwe, pensamento e conhecimento, em uma rede composta por seres diversos. Como foi mencionado por Belaunde (2005), é um traço comum em vários contextos etnográficos que o sangue seja pensamento corporificado que deve circular entre as pessoas para manter sua vitalidade.

Por sua parte, as águas dos rios, como o sangue do corpo da Mãe universal, percorrem o território vinculando as partes altas com as partes baixas, como indiquei anteriormente. No corpo, como no corpo-território, o sangue deve circular conectando opostos. Quando desce, vai entregando alimento e limpando; antes de subir, deve se limpar para não levar forças quentes para cima. Essa regulação, segundo Mamo Miguel, é feita pelo coração jwa vica, indicando que é a mesma função de limpeza e regulação que cumpre a SNSM no mundo. É por isso que a Serra é conhecida como o "coração do mundo", dando conta mais uma vez das relações fractais entre o corpo, o corpo-território e o cosmos.

A vitalidade dos corpos, como agrupamentos de relações vitais em diferentes escalas, depende da possibilidade de circulação das potências que permitem sua existência. A circulação se apresenta como um movimento oscilatório vertical, no qual se estabelecem vínculos, se regulam e se limpam as forças opostas complementárias, mediadas pelos anugwes do mamo e dos seres envolvidos. O movimento e a dinâmica de circulação parecem derivar da potência gansigna, que, ao afetar de uma maneira mais forte na sua necessária regulação, gera o movimento.

Aparentemente, o sangue menstrual é outro tipo de sangue. No caso de vários povos amazônicos, Belaunde (2005, 2006 apud ROSAS, 2019: 84) diferencia o sangue que circula do sangue derramado, este último relacionado com a morte, o parto e a menstruação, como uma substância que ativa presenças perigosas. Essa 
diferença está presente até certo ponto no caso Iku. Já comentei o potencial butisinu desse tipo de sangue, que pode ser associado ao perigo argumentado por Douglas ([1966] 2007) e Lévi-Strauss, (1981). No entanto, o butisinu não é um atributo fixo do sangue, é um potencial cuja agência depende do campo relacional no qual se inscreve. Em determinado sentido, o anugwe da dor que carrega o sangue menstrual, pode fazer mal a plantas e animais. Por outro lado, o risco implicado no butisinu está relacionado com sua potência de fertilização, capaz de intensificar eventos ou forças prejudiciais. Quer dizer que a potencialidade da morte e da fertilidade estão juntas no butisinu, de uma maneira incontrolada, motivo pelo qual é necessária sua regulação ritual. É interessante no caso Iku que o potencial butisinu não impede a circulação do sangue, mas implica uma circulação restrita. Como referiu Reichel-dolmatoff $(1947,1985,1991)$, as práticas rituais da SNSM dão muita importância à regulação da potência sexual. Sugiro que esses cuidados envolvem restrições da circulação do sangue menstrual, e não que ele pare de circular. Os vínculos estabelecidos com esse sangue têm lugar no ritual (entre o mamo, a mulher e o território), nos processos de cura do território e de outras pessoas, e para gerar vida. Essa possibilidade de circulação, mesmo restrita, implica a mediação do mamo como condição para a regulação desse sangue e sua associação com efeitos positivos e valores benignos, como manifestou Seykúmake. Esse sangue conecta o corpo com o corpo-território enquanto é entregue para curá-lo. Da mesma forma, o sangue pode curar graças à incorporação mediada de potências do território, materializadas nos objetos que compõem o $m \nVdash-$ rumsama.

As relações nas quais flui o sangue, não são restritas aos Iku. O universo da SNSM inclui aos não indígenas como "irmãos mais novos", também filhos da Mãe (Uribe, 1998). As relações com os não indígenas, da mesma forma que o sangue menstrual, implicam um risco e devem ser mediadas, dado que podem tanto alimentar como destruir sua existência. A análise da mediação do sangue dos "irmãos mais novos", materialização de um anugwe diferente, merece ser aprofundada em um trabalho posterior. Espero que as reflexões aqui apresentadas constituam um ponto de partida para futuras pesquisas que abordem essa questão.

Recebido em 28 de janeiro de 2020.

Aprovado em 20 de junho de 2020.

\section{Referências}

ARENAS, José. Sembrando vidas. La persona I'ku y su existencia entre lo visible y lo invisible. Tese de Doutorado, Antropologia Social, Instituto de Ciências Sociais, UnB, 2016.

BAPTISTA DA SILVA, Sergio. Cosmo-ontológica Guaraní: discutindo o estatuto de "objetos" e "recursos naturais". Revista de Arqueologia, 26 (1): 42-54, 2013.

BELAUNDE, Luísa Elvira. El recuerdo de Luna: genero, sangre y memoria entre los pueblos amazónicos. Lima: Fondo Editorial de la Facultad de Ciencias Sociales/UNMSM, 2005. 
BRAUN, Eliezer. Caos fractales y cosas raras. México: Fondo de Cultura Económica, 2003.

CAYÓN, Luis. Desde los templos y las lagunas: contribución al conocimiento del manejo ecológico y territorial indígena en la Sierra Nevada de Santa Marta. Boletín de Antropología, 17 (1): 209-234, 2003.

DE LA CADENA, Marisol. Earth Beings. Ecologies of Practice Across Andean Worlds. Durham: Duke University Press, 2015.

DE LA CADENA, M.; RISØR, H.; FELDMAN, J. Aperturas onto-epistemológicas: conversaciones con Marisol de la Cadena. Antípoda. Revista de Antropología y Arqueología, 32 (1): 159-177, 2018.

DOUGLAS, Mary. Pureza y peligro. Un análisis de los conceptos de contaminación y tabú. Buenos Aires: Ediciones Nueva Visión, [1966] 2007.

DOS SANTOS, Antonela; TOLA, Florencia. ¿Ontologías como modelo, método o política? Debates contemporáneos en antropología. Vá. Revista de Antropología del Programa de Postgrado en Antropología Social de la Universidad Nacional de Misiones, 29 (1), 2016.

DUQUE CAÑAS, Juan Pablo. Lo sagrado como argumento jurisdiccional en Colombia. La reclamación de tierras indígenas como argumento de Autonomía cultural en la sierra nevada de Santa Marta. Tese de Doutorado, História, Universidad Nacional de Colombia, 2009.

FACHEL, Ondina. Sangre, fertilidad y prácticas anticonceptivas. Revista Estudios Demográficos y urbanos, 9 (1): 237-254, 1994.

FERRO, María. Makruma. El Don Entre Los Iku de La Sierra Nevada de Santa Marta. Bogotá: Ediciones Uniandes, 2012.

FRIEDE, Juan. La explotación indígena en Colombia bajo el gobierno de las misiones: el caso de los Arhuacos de la SNSM. Bogotá, Punta de Lanza, 1963.

HORTA, Ana Milena. Tejiendo entre redes diversas: reflexiones a partir de una etnografía multisituada con los pueblos indígenas de la Sierra Nevada de Santa Marta, caribe colombiano. Revista Espaço Amerindio, 8 (1): 135-161, 2014.

HORTA, Ana Milena. Aproximación a la cosmopolítica de los colectivos indígenas de la Sierra Nevada de Santa Marta. Ley de sé, estado y patrimonio. Dissertação de Mestrado, Antropologia Social, UFRGS, 2015.

HORTA, Ana Milena. Cada Cuerpo contiene el mundo. Territorio, cuerpo y persona entre los Iku entre los iku del sector suroriental de la Sierra Nevada de Santa Marta, Colombia. Tese de Doutorado, Antropologia Social, UFRGS, 2020.

GIRALDO JARAMILLO, Natalia. Camino en espiral. Territorio sagrado y autoridades tradicionales en la comunidad indígena Iku de la Sierra Nevada de Santa Marta, Colombia. Revista Pueblos y Fronteras Digital [en línea], jun/nov. 2010.

LATOUR, Bruno. Nunca fuimos modernos. Buenos Aires: Siglo XXI Editores, 2007.

LATOUR, Bruno. Reagregando o social: uma introdução à teoria do Ator-Rede. Salvador, Edufba; Bauru: Edusc, 2012.

LEVÍ-STRAUSS, Claude. Las estructuras elementares del parentesco. Barcelona: Grupo Planeta, [1969] 1981. 
MCCALLUM, Cecilia. "O corpo que sabe. Da epistemologia kaxinawá para uma antropologia médica das terras baixas sul-americanas". In: ALVES, P. C.; RABELO, M.C. (org). Antropologia da saúde: traçando identidade e explorando fronteiras. Rio de Janeiro: Editora Fiocruz/Relume Dumará, 1998.

MORA, Pablo; VILLAFAÑA, Amado (eds.). Niwi Ukumin. Imagen y pensamiento de la Sierra Nevada de Santa Marta. Bogotá: Mincultura, 2018.

OGT - Organización Gonawindwa Tayrona. Jaba y jate: espacios sagrados del territorio ancestral Sierra Nevada de Santa Marta. Santa Marta: OGT, 2012.

OROZCO, José Antonio. Nabusimake, tierra de Arhuacos : monografía indígena de la Sierra Nevada de Santa Marta. Bogotá: Escuela Superior de Administración Pública, 1990.

PATERNINA, Hugo. "Los pueblos indígenas de la Sierra Nevada de Santa Marta: una visión desde el cuerpo, el territorio y la enfermedad". In: VIGOYA, Mara Viveros; ARIZA, Gloria Garay (eds.). Cuerpo, diferencias y desigualdades. Bogotá: Universidad Nacional de Colombia, 1999. pp. 272-296.

REICHEL-DOLMATOFF, Gerardo. Aspectos económicos entre los indios de la Sierra Nevada. Boletín de arqueología, 2 (5-6), 1947.

REICHEL-DOLMATOFF, Gerardo. Templos Kogui. Introducción al simbolismo y a la astronomía del espacio sagrado. Revista Colombiana de Antropologia, 19 (1), 1975

REICHEL-DOLMATOFF, Gerardo. The Loom of Life: A Kogui Principle of Integration. Journal of Latin American Lore, 4 (1): 5-25, 1978.

REICHEL-DOLMATOFF, Gerardo. Los Kogui: una tribu de la Sierra Nevada de Santa Marta, Colombia. Bogotá: PROCULTURA/Nueva Biblioteca Colombiana/Editorial Presencia, 1985.

REICHEL-DOLMATOFF, Gerardo. The Great Mother and the Kogui Universe: a concise overview. Journal of Latin American Lore, 13 (1): 73-113, 1987.

REICHEL-DOLMATOFF, Gerardo. Los Ika. Sierra Nevada de Santa Marta. Notas Etnográficas. 1946-1966. Bogotá: Universidad Nacional de Colombia, 1991.

RODRIGUEZ, Edna. Megaproyectos, movimiento y organización indígena en la Sierra Nevada de Santa Marta: el caso de la iniciativa de Embalse de Besotes. Dissertação de Mestrado, Antropologia Social, Universidad Nacional de Colombia, 2014.

ROSAS, Diana. Menstruación, epistemología y etnografía amazónica. Maguaré, 33 (1): 75-107, 2019.

SAHLINS, Marshal. Islas de historia. La muerte del capitán Cook. Metáfora, antropología e historia. Barcelona, Gedisa, 1997.

SANTOS GRANERO, F. Beinghood and People-making in native amazonia. a constructional approach with a Perspectival coda. Journal of Ethnographic Theory, 2 (1): 181-211, 2012.

SEEGER, A., DA MATTA, R.; VIVEIROS DE CASTRO, E. A construção da Pessoa nas sociedades indígenas brasileiras. Boletim do Museu Nacional, 32 (1): 2-19, 1979. 
STENGERS, Isabelle. Experimenting with refrains. Subjectivity and the challenge of escaping modern dualism. Subjectivity, 22 (1): 38-59, 2008.

STRATHERN, Marilyn. O gênero da Dádiva. Problemas com as mulheres e problemas com a sociedade na Melanésia. Campinas: Unicamp, 2006.

TAYLER, Donald. The Coming of the Sun. A Prologue to Ika Sacred Narrative. Oxford: Pitt Rivers Museum/Oxford University, 1997.

TAYLOR, Anne Christine. The Soul's Body and Its States: An Amazonian Perspective on the Nature of Being Human. The Journal of the Royal Anthropological Institute, 2 (2): 201-215, 1996.

TOLA, Florencia. Yo no estoy solo en mi cuerpo: Cuerpos-Personas Múltiples entre los Tobas del Chaco Argentino. Buenos Aires: Biblos/Culturalia, 2012.

TORRES SOLIS, Hermes Enrique. Resurgiendo de la pérdida: desarrollo organizativo del pueblo Arhuaco, período 2000-2003. TCC, Antropologia, Universidad de Los Andes, 2004.

ULLOA, Astrid. La construcción del nativo ecológico. Complejidades, paradojas y dilemas de la relación entre los movimientos indígenas y el ambientalismo en Colombia. Bogotá: ICANH, 2004.

URIBE, Carlos Alberto. De la Sierra Nevada de Santa Marta, sus ecosistemas, indígenas y antropólogos. Revista de Antropología, 4 (1): 5-36, 1988.

URIBE, Carlos Alberto. De la vitalidad de nuestros hermanos mayores de la nevada. Revista de Antropología y arqueología, Bogotá, v. 10, n. 2, 1998, p. 9-92.

VARGAS TOVAR, Yalmar. Configuración del territorio Arhuaco en la Sierra Nevada de Santa Marta: la zona de ampliación de del resguardo Arhuaco. TCC, Antropologia, Universidad de Los Andes, 2004.

VÍCTORA, Ceres. Mulher, sexualidade e reprodução: representações do corpo em urna vila das classes populares em Porto Alegre. Dissertação de Mestrado, Antropologia, UFRGS, 1991.

VILAÇA, Aparecida. Chronically instable bodies: reflections on Amazonian corporalities. Journal of the Royal Anthropological Institute, 11 (1): 445- 464, 2005.

VILLEGAS, Marta. Los Wiwa, nociones de equilibrio y movimiento. TCC, Antropologia, Universidad de Los Andes, 1999.

WAGNER, Roy. "The Fractal Person". In: STRATHERN, Marilyn; GODELIER, Maurice (orgs.). Big Men and Great Men: Personifications of Power in Melanesia. Cambridge: Cambridge University Press, 1991.

YOSOKWI. Naboba. Visión ancestral del agua del pueblo Arhuaco. Dir.: Amado Villafaña, (dir). Documentário, Colômbia, 2015

ZHIGONESHI. Resistencia en la línea negra. Dir.: Saúl Gil, Silvestre Gil Sarabata, Amado Villafaña. Documentário, Colômbia, 84', 2011. 